\title{
bitHERO: Um Jogo para Auxílio no Aprendizado de Circuitos Digitais
}

\author{
Antonio Crispim A. Neto ${ }^{1}$, Joacy Mesquita da Silva ${ }^{1}$, Victor Travassos Sarinho ${ }^{1}$ \\ ${ }^{1}$ Curso de Engenharia de Computação \\ Universidade Estadual de Feira de Santana (UEFS) \\ CEP: 44036-900 - Avenida Transnordestina - S/N - Novo Horizonte \\ Feira de Santana - Bahia - Brasil \\ \{antoniocan36, joacymsilva,vsarinho\}@gmail.com
}

\begin{abstract}
This work presents bitHERO, a boolean game developed with the purpose of assisting, in a playful way, the learning of digital circuits, prioritizing initially the teaching of logic gates. The motivations for the development of the game, the resources used for it, and the dynamics of the game implemented are presented. Proposals for improvement and expansion of the game are also shown.
\end{abstract}

Resumo. Este trabalho apresenta o bitHERO, um jogo boole desenvolvido com intuito de auxiliar, de forma lúdica, o aprendizado de circuitos digitais, priorizando inicialmente o ensino das portas lógicas. São apresentadas as motivações para o desenvolvimento do jogo, os recursos utilizados para isso, e a dinâmica do jogo implementado. Também são mostradas propostas de melhoria e ampliação do jogo.

\section{Introdução}

Realizar cálculos abstratos é uma tarefa que pode se tornar muito difícil para alguns estudantes do ensino médio, ou até mesmo universitários. Possivelmente uma das razões para tal dificuldade seja a falta de um bom desenvolvimento do raciocínio lógico.

Em cursos de TI o fraco raciocíonio lógico pode vir a atrapalhar o desempenho do estudante em disciplinas como Circuitos Digitais, por exemplo, onde o raciocínio lógico é bastante exigido. De fato, o desenvolvimento de estratégias lúdicas para tornar o conhecimento matemático mais eficiente é gerado pela dificuldade em compreender os conhecimentos matemáticos a partir de estratégias abstratas [Girelli and Bezerra ].

Visando fomentar o desenvolvimento do raciocínio lógico e o pensamento computacional para que sirva de apoio às diciplinas de TI, em especial Circuitos Digitais, iniciou-se o desenvolvimento do bitHERO, um jogo musical focado em lógica binária e álgebra booleana que tenta de forma lúdica e desafiadora ensinar conceitos de Circuitos Digitais.

\section{Metodologia}

Pessoas que jogam videogame tem demonstrado um melhor desempenho em uma série de habilidades cognitivas, como atenção, processamento perceptual e funções executivas, quando comparados a não jogadores de videogames [Boot et al. 2008]. Como exemplo, 
VII Congresso Brasileiro de Informática na Educação (CBIE 2018)

Anais do XXIX Simpósio Brasileiro de Informática na Educação (SBIE 2018)

jogos do tipo Guitar Hero e Rock Band melhoram a coordenação entre olhos e mãos do jogador, bem como forçam o mesmo a tomar decisões imediatas, devido ao pouco tempo de resposta disponível para apertar os botões corretamente [Elia 2015].

Jogos boole tem como principal objetivo desenvolver o raciocínio lógico com o uso de objetos lúdicos [Girelli and Bezerra ]. Partindo dessa premissa, o bitHERO foi desenvolvido com base nas mecânicas do clássico Guitar Hero, trazendo para o escopo do jogo a temática de circuitos digitais e lógica binária.

Para o desenvolvimento do bitHERO foram utilizados recursos 2D da plataforma Unity, tendo como base a linguagem C\# para a criação de todos os scripts do jogo. A dinâmica do jogo consiste em acertar as saídas das portas lógica antes que elas cheguem ao fim da tela. Seguindo a mesma dinâmica do Guitar Hero, porém ao invés de notas simples, serão portas lógicas com entradas. Cada cor de porta lógica, possui duas teclas associadas a ela, uma para a saída lógica 0 e outra para a saída lógica 1 . Cabe ao jogador, além de acertar a tecla correspondente a cor certa, escolher a saída exata da porta. A Figura 1 ilustra um exemplo de porta lógica utilizada no jogo. Ao todo são utilizados dois tipos de portas lógicas, a AND e a OR. A lógica inversora (NOT) se faz presente nas portas NAND, AND com saída inversora, e NOR, OR com saída inversora.

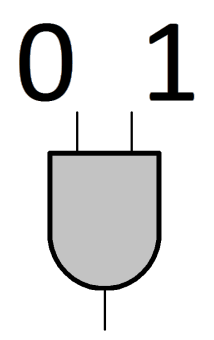

Figura 1. Exemplo de porta AND com entrada "01".

A trilha sonora do jogo foi extraída de músicas sem copyright, sendo um projeto futuro a inclusão de músicas de artistas locais. Com relação a animação do jogo, utilizouse a técnica de Pixel Art para criar o personagem principal do jogo, neste caso o BitBoy, que acompanha o jogador na tela durante as fases do mesmo.

Para a sincronização das portas lógicas com a música a ser tocada, foi criado um script extra para os desenvolvedores, o "Modo Criação". Nele, se torna possivel ouvir a música e gerar as portas lógicas através da própria execução do jogo, onde o desenvolvedor pode seguir o ritmo da mesma e gerar as notas da maneira que achar conveniente.

\section{Resultados Obtidos}

Com relação ao jogo implementado, este se resume em três telas, a Tela Inicial, com a apresentação das opções do jogo, a Tela Principal, onde a dinâmica do jogo acontece, e a Tela de Ajuda, onde são apresentadas as tabelas-verdade das portas lógicas presentes no jogo.

A Figura 2(a) apresenta a Tela Inicial do bitHERO. Nela são apresentados o nome, a logotipo do jogo e o personagem do jogo (BitBoy). Também são apresentados os botões: "Jogar", que ao ser clicado leva o usuário à Tela Principal do jogo; "Ajuda", que 
VII Congresso Brasileiro de Informática na Educação (CBIE 2018)

Anais do XXIX Simpósio Brasileiro de Informática na Educação (SBIE 2018)

leva o usuário à Tela de Ajuda; "Créditos", que leva o usuário à tela que informa sobre os desenvolvedores; e "Sair", que leva o usuário a sair da aplicação.

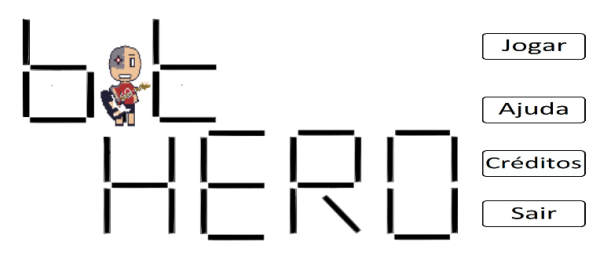

(a) Tela Inicial

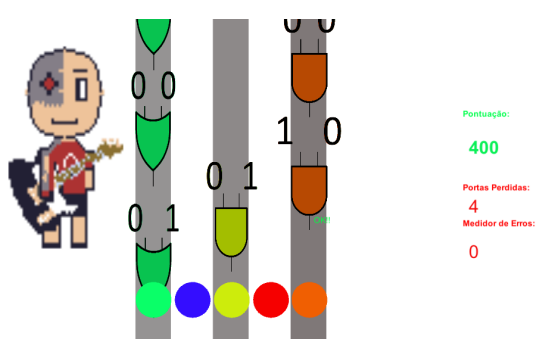

(b) Tela Principal

Figura 2. Telas Inicial e Principal do jogo bitHERO.

A Figura 2(b) apresenta a Tela Principal do bitHERO. À esquerda pode ser visto o BitBoy, que traz uma animação durante a música, indicando satisfação ou não com o desempenho do usuário. No centro pode ser vista a plataforma por onde descem as portas lógicas e suas determinadas entradas. A plataforma é dividida em cinco partes, referentes às cinco cores (verde, azul, amarelo, vermelho e laranja) de portas que podem aparecer durante a música. À direita são mostradas a pontuação do jogador, a quantidade de notas erradas, e o medidor de erro.

A Figura 3 apresenta a Tela de Ajuda do bitHERO. Para a versão inicial, foram utilizadas as portas lógicas AND, OR, NAND e NOR de duas entradas. Portanto, na tela estão indicadas as devidas saídas destas portas ao receberem como entrada " 00 ", "01", "10" e "11". Além disso, à esquerda da tela há os comandos a serem ativados no jogo.

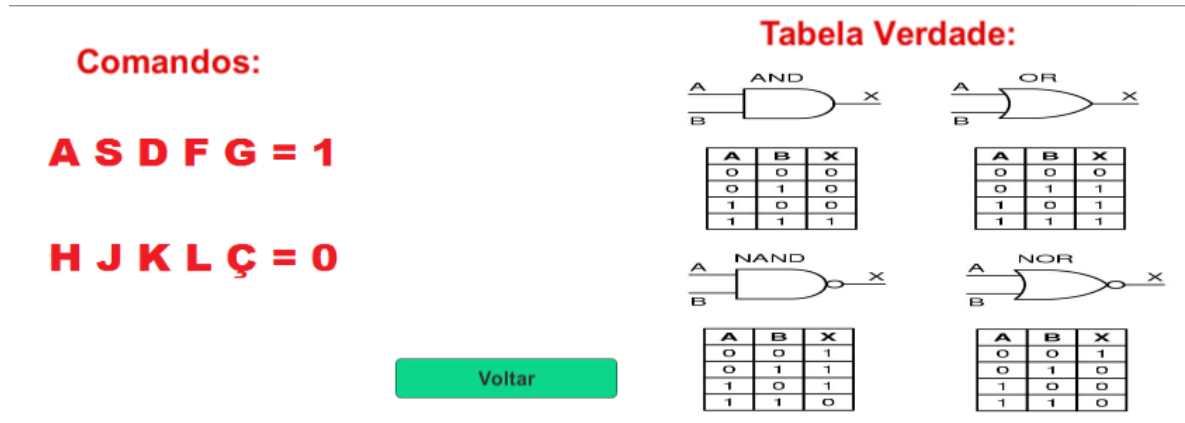

Figura 3. Tela de Ajuda do bitHERO.

Quanto a dinâmica do jogo, podem ser destacados os critérios de vitória e derrota. $\mathrm{O}$ jogador perde a partida se o seu medidor de erro chegar a 7 ou se perder 7 notas. $\mathrm{O}$ medidor diminui em 1 a cada acerto. Para vencer a fase o jogador deve chegar até o final da música, na qual será mostrada a sua pontuação final.

Se um dos critérios de derrota forem cumpridos, o jogo é interrompido e a tela de Game Over ( Figura 4(a)) é mostrada. Ela apresenta uma animação do BitBoy chorando, com uma música triste ao fundo, junto com a opção de voltar para a Tela Inicial do jogo. Caso o jogador consiga chegar ao final da música, a tela de sucesso (Figura 4(b)) é mostrada ao jogador, a qual apresenta a pontuação final do jogador durante a fase. 


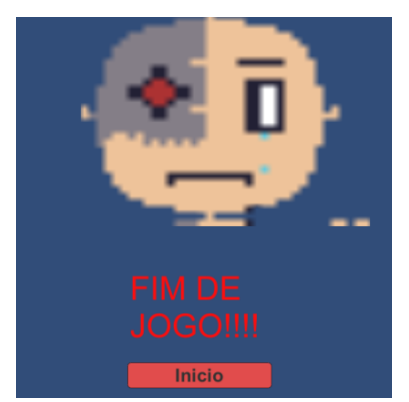

(a) Tela de Game Over

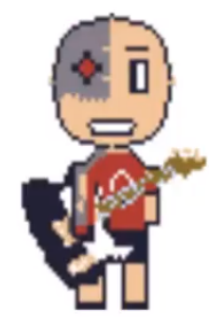

(b) Tela de Sucesso

\section{Parabéns!}

Sua Pontuação :

2900
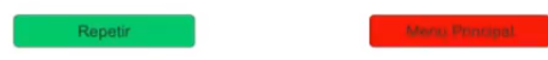

Figura 4. Telas de Game Over e de Sucesso do jogo bitHERO.

\section{Conclusões e Trabalhos Futuros}

Este artigo apresentou o bitHERO, um jogo boole que tem como principal objetivo estimular o raciocínio lógico e o aprendizado de circuitos digitais. O jogo apresenta um ambiente iterativo e por se basear em mecânicas de jogos conhecidos pode alcançar um alto nível de diversão.

Atualmente o jogo possui apenas uma fase, algo que será expandido futuramente com o acréscimo de mais músicas com níveis de desafios mais elevados. Na versão atual, são trabalhadas quatro portas lógicas, algo que será expandido com a adição da porta XOR (OR exclusiva) e de entradas inversoras.

Também como trabalho futuro, pode ser destacado a implementação do "Modo Criação" online para os jogadores, que poderão jogar e compartilhar suas músicas gerando assim desafios personalizados e compartilháveis.

\section{Referências}

Boot, W. R., Kramer, A. F., Simons, D. J., Fabiani, M., and Gratton, G. (2008). The effects of video game playing on attention, memory, and executive control. Acta psychologica, 129(3):387-398.

Elia, F. (2015). Como videogames podem turbinar seu cérebro. Disponível em: goo.gl/MruaHP. Acesso em 07 de Julho de 2018.

Girelli, M. and Bezerra, R. C. Matemática e raciocínio lógico: Trabalhando e discutindo os jogos boole. 